\title{
Extinction of Cocaine Seeking Requires a Window of Infralimbic Pyramidal Neuron Activity after Unreinforced Lever Presses
}

\author{
Andrea L. Gutman, ${ }^{1}$ Kelle E. Nett, ${ }^{1,2}$ Caitlin V. Cosme, ${ }^{1}$ Wensday R. Worth, ${ }^{1}$ Subhash C. Gupta, ${ }^{3}$ John A. Wemmie, ${ }^{2,3}$ \\ and $\odot$ Ryan T. LaLumiere ${ }^{1,2}$ \\ ${ }^{1}$ Department of Psychological and Brain Sciences, ${ }^{2}$ Interdisciplinary Graduate Program in Neuroscience, and ${ }^{3}$ Department of Psychiatry, University of \\ Iowa, Iowa City, Iowa 52242
}

The infralimbic cortex (IL) mediates extinction learning and the active suppression of cocaine-seeking behavior. However, the precise temporal relationship among IL activity, lever pressing, and extinction learning is unclear. To address this issue, we used activity-guided optogenetics in male Sprague Dawley rats to silence IL pyramidal neurons optically for 20 s immediately after unreinforced lever presses during early extinction training after cocaine self-administration. Optical inhibition of the IL increased active lever pressing during shortened extinction sessions, but did not alter the retention of the extinction learning as assessed in ensuing extinction sessions with no optical inhibition. During subsequent cued reinstatement sessions, rats that had previously received optical inhibition during the extinction sessions showed increased cocaine-seeking behavior. These findings appeared to be specific to inhibition during the post-lever press period because IL inhibition given in a noncontingent, pseudorandom manner during extinction sessions did not produce the same effects. Illumination alone (i.e., with no opsin expression) and food-seeking control experiments also failed to produce the same effects. In another experiment, IL inhibition after lever presses during cued reinstatement sessions increased cocaine seeking during those sessions. Finally, inhibition of the prelimbic cortex immediately after unreinforced lever presses during shortened extinction sessions decreased lever pressing during these sessions, but had no effect on subsequent reinstatement. These results indicate that IL activity immediately after unreinforced lever presses is necessary for normal extinction of cocaine seeking, suggesting that critical encoding of the new contingencies between a lever press and a cocaine reward occurs during that period.

Key words: medial prefrontal cortex; optogenetics; reinstatement; retention; self-administration

Significance Statement

The infralimbic cortex (IL) contributes to the extinction of cocaine-seeking behavior, but the precise relationship among IL activity, lever pressing during extinction, and extinction learning has not been elucidated using traditional methods. Using a closed-loop optogenetic approach, we found that selective inhibition of the IL immediately after unreinforced lever pressing impaired within-session extinction learning and promoted the subsequent cued reinstatement of cocaine seeking. These studies suggest that IL activity immediately after the instrumental response during extinction learning of cocaine seeking encodes information required for such learning and that altering such activity produces long-lasting changes in subsequent measures of cocaine craving/relapse.

\section{Introduction}

Accumulating evidence indicates that the infralimbic cortex (IL), a region of the ventromedial prefrontal cortex (vmPFC), regu-

Received Dec. 1, 2016; revised May 16, 2017; accepted May 17, 2017.

Author contributions: A.L.G. and R.T.L. designed research; A.L.G., K.E.N., C.V.C., W.R.W., and S.C.G. performed research; J.A.W. contributed unpublished reagents/analytic tools; A.L.G. and R.T.L. analyzed data; A.L.G. and R.T.L. wrote the paper.

This work was supported by the National Institutes of Health (Grants DA034684 and MH104384 to R.T.L., Grant DA037216-02 to R.T.L. and J.A.W., and Grant HL113863 to J.A.W.), the Department of Veterans Affairs (VA Merit Review Grant IBX000741B to J.A.W.), and the Brain \& Behavior Research Foundation (NARSAD Independent Inves- lates the extinction of cocaine-seeking behavior. In rats trained to self-administer cocaine, pharmacologically inhibiting and activating the IL after extinction training sessions impairs and enhances, re-

tigator Award to J.A.W.). We thank Teresa Treat and Victor Navarro for assistance with statistical analysis and Jason Radley and Sara Romig-Martin for assistance with fluorescence imaging.

The authors declare no competing financial interests.

Correspondence should be addressed to Andrea L. Gutman, Ph.D., Department of Psychological and Brain Sciences, 11 Seashore Hall E, University of lowa, lowa City, IA 52242. E-mail: Andrea-Schwager@uiowa.edu. D0I:10.1523/JNEUROSCI.3821-16.2017

Copyright $\odot 2017$ the authors $\quad 0270-6474 / 17 / 376075-12 \$ 15.00 / 0$ 
spectively, the retention of extinction learning (LaLumiere et al., 2010). Similarly, blocking the neurotrophic factors bFGF or FGF2 in the IL during extinction training for cocaine seeking increases the retention of the extinction learning (Hafenbreidel et al., 2015). Moreover, evidence suggests that the IL actively suppresses cocaine seeking after lever pressing is extinguished. IL inactivation and activation after extinction training induces cocaine seeking and suppresses cued and cocaine-induced reinstatement, respectively (Peters et al., 2008; LaLumiere et al., 2012). Akin to the results with self-administration, optical inhibition of pyramidal neurons in vmPFC impairs extinction learning for cocaine conditioned place preference (Van den Oever et al., 2013). Together, these findings provide strong evidence that the IL is involved in the extinction of cocaine seeking and specifically that the IL is a critical mediator of the ability of extinction training to suppress subsequent cocaine seeking.

Evidence from the extinction of tone fear conditioning suggests that specific and temporally restricted changes in IL activity after presentation of the conditioned stimulus alone (i.e., the tone) are critically involved in the extinction learning (Milad and Quirk, 2002). Optical inhibition of IL glutamatergic neurons coinciding with tone delivery during extinction impairs retention of extinction learning (Do-Monte et al., 2015). However, several differences between tone fear conditioning and cocaine selfadministration exist, including significantly distinct temporal characteristics that make addressing this issue in the extinction of cocaine seeking more challenging. In contrast to tone fear conditioning, in which the foot shock is typically delivered at a specific time point after the tone, cocaine self-administration involves several consequences after a lever press that serve as either primary reinforcers (increased dopamine efflux in the brain from the cocaine infusion) or as conditioned reinforcers (e.g., light and tone cues concurrent with the infusion, the peripheral effects of cocaine). Therefore, the period of extinction encoding may occur over a longer period compared with the extinction of tone fear conditioning. Moreover, unlike extinction of tone fear conditioning, in which the conditioned stimulus and optical manipulations can be given in a manner controlled by the experimenter, the extinction of cocaine seeking depends on the behavior of the animal.

Whereas the cocaine self-administration studies described above suggest that IL activity may contribute to such encoding, they largely relied on pharmacological manipulations, which are unable to alter IL activity with the temporal precision necessary to address this idea. Indeed, based on the evidence in the literature, it is unclear whether general IL activity during/after an extinction session is important or if there is a specific temporal window (e.g., immediately after an unreinforced lever press) in which IL activity is critical for extinction learning. Therefore, to address these issues, we used a "closed-loop," activity-guided optogenetic approach (Grosenick et al., 2015) in which optical inhibition of pyramidal neurons was triggered by the animal pressing the lever during extinction training. Specifically, the inhibitory opsin eArchT3.0, under the control of the CaMKII $\alpha$ promoter, was expressed in the IL or prelimbic (PL) subregions of the mPFC. Optical inhibition was applied for $20 \mathrm{~s}$ immediately after each unreinforced lever press during early extinction training after cocaine self-administration to disrupt activity during the putative encoding period and determine whether such inhibition alters extinction learning. Moreover, to determine whether this manipulation produced long-lasting changes in cocaine seeking, rats also underwent different forms of reinstatement testing after the completion of extinction training.

\section{Materials and Methods}

\section{Subjects}

Male Sprague Dawley rats (Charles River Laboratories $\sim 300 \mathrm{~g}$ at the time of surgery, $n=119$ ) were individually housed in a temperaturecontrolled environment and maintained on a $12 \mathrm{~h}$ reverse light/dark cycle. Rats were given $\sim 20 \mathrm{~g}$ of rat chow per day. Methods were approved by the University of Iowa Institutional Animal Care and Use Committee and were in compliance with National Institutes of Health guidelines for the care of laboratory animals. Rats underwent behavioral training $6 \mathrm{~d}$ per week.

\section{Surgery}

Rats were anesthetized with ketamine $\mathrm{HCl}(100 \mathrm{mg} / \mathrm{kg}$, i.m. ) and xylazine $\mathrm{HCl}(6 \mathrm{mg} / \mathrm{kg}$, i.m.). Meloxicam ( $2 \mathrm{mg} / \mathrm{kg}$, s.c.) was administered as an analgesic before surgery, as well as $24 \mathrm{~h}$ after surgery.

For catheter implantation, a $14 \mathrm{~cm}$ piece of SILASTIC tubing with a silicone ball affixed $4 \mathrm{~cm}$ from a beveled end was inserted into the right jugular vein. The opposite end of the tubing was externalized between the shoulder blades and connected to a harness with a 22-gauge guide cannula, which was used for the delivery of cocaine. Catheters were flushed $6 \mathrm{~d}$ per week with $0.1 \mathrm{ml}$ of heparinized saline and glycerol lock solution to ensure catheter patency.

For virus injection and fiber optic implantation, rats were placed in a small animal stereotax (Kopf Instruments). Rats were injected with virus (AAV5-CaMKII $\alpha$-eArchT3.0-eYFP or AAV5-CaMKII $\alpha$-eYFP) targeted bilaterally at the IL. Double-barreled 33-gauge injectors (Plastics One) were centered over the midline (1.2 mm center-to-center distance) and injections $(0.3 \mu \mathrm{l}$ at a rate of $0.1 \mu \mathrm{l} / \mathrm{min})$ were targeted $3.0 \mathrm{~mm}$ anterior to bregma and 5.5 or $3.7 \mathrm{~mm}$ ventral to skull surface for IL and PL targets, respectively. Injections were left in place for $7 \mathrm{~min}$ to allow diffusion of the virus. During the same surgery, rats were implanted with indwelling optical fibers glued in multimode stainless alloy ferrules (Thorlabs). IL coordinates were as follows: $3.0 \mathrm{~mm}$ anterior, $1.5 \mathrm{~mm}$ lateral, and $4.5 \mathrm{~mm}$ ventral to bregma at a $9^{\circ}$ angle. PL optical fiber coordinates were as follows: $3.0 \mathrm{~mm}$ anterior, $1.3 \mathrm{~mm}$ lateral, and $2.9 \mathrm{~mm}$ ventral to bregma at a $10^{\circ}$ angle. Dust caps were maintained on the externalized end of the ferrule throughout the experiments. Rats received $3 \mathrm{ml}$ of sterile saline subcutaneously after surgery for rehydration.

\section{Electrophysiological verification}

Electrophysiological experiments were conducted to confirm that application of a $561 \mathrm{~nm}$ laser to mPFC neurons expressing AAV5-CaMKII $\alpha$ eArchT3.0-eYFP inhibited neuronal firing. The virus was targeted to the IL, as described above. Three weeks later, $300-\mu \mathrm{m}$-thick coronal brain slices containing mPFC were prepared using a Vibratome 1000 Plus in ice-cold slicing buffer containing the following (in $\mathrm{mm}$ ): 225 sucrose, 26 $\mathrm{NaHCO}_{3}, 1.2 \mathrm{KH}_{2} \mathrm{PO}_{4}, 1.9 \mathrm{KCl}, 1.1 \mathrm{CaCl} 2,2 \mathrm{MgSO}_{4}$, and $10 \mathrm{D}$-glucose continuously bubbled with $95 \% \mathrm{O}_{2}$ and $5 \% \mathrm{CO}_{2}$. Slices were submerged in $34^{\circ} \mathrm{C}$ artificial CSF (aCSF) for $30 \mathrm{~min}$ and allowed to recover for another $30 \mathrm{~min}$ at room temperature. Slices were subsequently transferred to the recording chamber, superfused with aCSF $(2.0 \mathrm{ml} / \mathrm{min})$ at nearly physiological temperature $\left(30-32^{\circ} \mathrm{C}\right)$, and equilibrated for at least 15 min before each recording.

Functional expression of AAV5-CaMKII $\alpha$-eArchT3.0-eYFP in the IL was confirmed with voltage- and current-clamp whole-cell recordings using an Axopatch 700B amplifier (Molecular Devices). Borosilicate recording glass pipettes with resistances ranging between 3 and $6 \mathrm{M} \Omega$ were pulled using standard borosilicate capillaries by a Flaming-Brown electrode puller (P-97; Sutter Instruments). Potassium gluconate based patch solution containing the following (in $\mathrm{mm}$ ): 125 potassium gluconate, $20 \mathrm{KCl}, 10 \mathrm{NaCl}, 2 \mathrm{Mg}$-ATP, $0.3 \mathrm{Na}$-GTP, 10 HEPES, 0.2 EGTA, $\mathrm{pH} 7.3$, adjusted with $\mathrm{KOH}$ was used for the whole-cell recordings. Cells were held at $-70 \mathrm{mV}$ holding potential during voltage-clamp recording and $10 \mathrm{~mW}$ of the $561 \mathrm{~nm}$ yellow laser was applied for $20 \mathrm{~s}$. During current-clamp recording, $20 \mu \mathrm{M}$ CNQX, $100 \mu \mathrm{M}$ picrotoxin, and $100 \mu \mathrm{M}$ dl-AP5 were added in aCSF (recording solution) to block AMPA receptors, GABA receptors, and NMDA receptors, respectively. Currents were amplified, sampled at $10 \mathrm{kHz}$, and digitized by a DigiData 1550A. The resting membrane potential of cells were maintained at $-55 \mathrm{mV}$ and a 75 
pA current was injected to evoke action potentials. The $561 \mathrm{~nm}$ yellow laser was applied for $20 \mathrm{~s}$ and analysis was subsequently performed in Clampfit software (Axon).

\section{Optical inhibition}

During sessions in which rats received optical inhibition or the sham control, the bilateral ferrules were connected to fiber-optic leashes via a split ceramic sleeve. These fiber-optic leashes were threaded through a protective metal spring leash and FC/PC connectors on the opposite ends were attached to 2:1 splitter to permit bilateral stimulation (FONT Canada). All optical fibers were covered for protection and to prevent the escape of visible light. The single end of the splitter attached to an optical commutator (Doric Lenses). A patch cable linked the commutator to a laser with a multimode fiber coupler for an FC/PC connection $(300 \mathrm{~mW}$, $561 \mathrm{~nm}$; Shanghai Lasers or OEM Lasers). Laser output was measured using a power meter and was adjusted to $\sim 10 \mathrm{~mW}$ at the fiber tip, based on previous work (Yizhar et al., 2011; Huff et al., 2013). Sham controls received ferrule implants and were attached in the same manner as the experimental group except that the laser was not turned on.

\section{Cocaine self-administration and extinction}

Self-administration training sessions were performed $6 \mathrm{~d}$ per week in standard operant boxes, housed within sound-attenuating chambers (Med Associates), and equipped with a central reward receptacle flanked by two retractable levers. Cue lights were located directly above the levers and a $4500 \mathrm{~Hz}$ Sonalert module was used as the tone generator. A house light on the opposite wall of the operant chamber was illuminated throughout the training sessions. After $24 \mathrm{~h}$ of food deprivation, rats were trained in an overnight session to lever press for $45 \mathrm{mg}$ food pellets (Dustless Precision Pellets; Bio-serv) on an FR1 schedule of reinforcement. One day after food training, rats began training $6 \mathrm{~d}$ per week on the $2 \mathrm{~h}$ cocaine self-administration task.

During the first $2 \mathrm{~d}$ of cocaine self-administration, a lever press on the active (right) lever resulted in a $50 \mu \mathrm{l}$ cocaine infusion (100 $\mu$ g cocaine per infusion, dissolved in $0.9 \%$ sterile saline; cocaine kindly provided by the National Institute on Drug Abuse) and the presentation of light and tone cues. A $20 \mathrm{~s}$ time-out period followed each infusion, during which active lever presses had no scheduled consequence. After at least $2 \mathrm{~d}$ of self-administration training with at least 15 infusions on the last day, rats were trained on the full self-administration task, in which the active lever was retracted for $20 \mathrm{~s}$ immediately after each infusion. This was done so that, during optical manipulations as part of the extinction experiment, 20 s periods of inhibition were linked with specific lever presses and to ensure that no lever presses could occur during the inhibition period. This time period of inhibition was chosen because prior work indicated that an intravenous cocaine infusion requires $\sim 10 \mathrm{~s}$ to increase dopamine levels in the brain and that this increase can persist up to $20 \mathrm{~s}$ (Aragona et al., 2008). Therefore, we considered it likely that neural encoding regarding the lever press and lack of reinforcer may persist up to $20 \mathrm{~s}$ after the press.

After cocaine self-administration, rats underwent extinction training, followed by reinstatement sessions. To enter the extinction phase of training, rats had to complete at least $12 \mathrm{~d}$ of cocaine self-administration with $>10$ infusions on 10 of the days and $>15$ infusions on each of the final $2 \mathrm{~d}$. For group assignment, rats were matched based on the number of infusions over the last $3 \mathrm{~d}$ of self-administration. Table 1 shows the average number of infusions \pm SEM over the last $3 \mathrm{~d}$ of selfadministration. There were no significant differences between groups, demonstrating the effectiveness of the matching. The procedures for each experiment are described below.

\section{Experiment 1: IL inhibition after unreinforced lever presses}

Experiment 1 investigated whether neuronal activity in the IL immediately after unreinforced lever presses mediates the extinction of cocaine-seeking behavior. During Experiment 1a, at least $12 \mathrm{~d}$ of cocaine self-administration were followed by $5 \mathrm{~d}$ of shortened ( $30 \mathrm{~min}$ ) extinction sessions. During these extinction sessions, an active lever press triggered retraction of the active lever as well as optical illumination. The illumination lasted for $20 \mathrm{~s}$, at which point the lever was reinserted. At least $7 \mathrm{~d}$ of $2 \mathrm{~h}$ extinction sessions followed the shortened extinction sessions, during which no illumination was deliv-

\section{Table 1. Average cocaine infusions during the last $3 \mathrm{~d}$ of self-administration} presented as mean \pm SEM

\begin{tabular}{ll}
\hline Experiment & Infusions \\
\hline 1a & \\
Sham & $40.50 \pm 5.81$ \\
Laser & $49.57 \pm 8.351 \mathrm{~b}$ \\
Sham & $50.38 \pm 2.71$ \\
$\quad$ Laser & $43.33 \pm 4.57$ \\
1c $\quad$ \\
Sham & $49.52 \pm 6.45$ \\
$\quad$ Laser & $47.36 \pm 5.55$ \\
2 & \\
Sham & $79.50 \pm 15.61$ \\
Laser & $65.83 \pm 10.57$ \\
Sham & $54.90 \pm 5.21$ \\
Laser & $51.81 \pm 3.87$ \\
4a & $61.18 \pm 6.41$ \\
4b & $45.08 \pm 6.99$ \\
\hline
\end{tabular}

ered. The extinction data from these $7 \mathrm{~d}$ served as an index of retention of the extinction learning from the shortened sessions. The choice for $5 \mathrm{~d}$ of shortened extinction sessions, followed by full-length sessions, was based on earlier work (LaLumiere et al., 2010; Hafenbreidel et al., 2014; Hafenbreidel et al., 2015). In particular, this design reduces the amount of extinction learning that occurs during each extinction session, thereby enabling the fulllength extinction sessions to better serve as an index of retention.

After this extinction period, rats underwent reinstatement testing. To undergo reinstatement, rats had to have at least $7 \mathrm{~d}$ of $2 \mathrm{~h}$ extinction sessions and $<25$ lever presses on the 2 consecutive extinction days immediately before the reinstatement session. For cued reinstatement, active lever presses led to lever retraction and produced the light and tone cues previously associated with the cocaine infusion but did not produce a cocaine infusion. During the cocaine-primed reinstatement session, rats received a cocaine injection $(10 \mathrm{mg} / \mathrm{kg}$, i.p.) immediately preceding the session, during which active lever presses resulted only in retraction of the lever. Cue + cocaine-primed reinstatement combined the cued and cocaine-primed reinstatement procedures. At least three $2 \mathrm{~h}$ extinction sessions occurred between reinstatements and rats were required to execute $<25$ active lever presses on the $2 \mathrm{~d}$ preceding each reinstatement. It is critical to note that, in all experiments except Experiment 4, all illumination/inhibition was given only during the first $5 \mathrm{~d}$ of extinction.

Two additional control experiments were then conducted. For Experiment $1 \mathrm{~b}$, the surgical procedures, experimental timeline, and design were as described for Experiment 1a with the sole exception that, during the shortened extinction sessions, the IL was inhibited optically during the five shortened (30 $\mathrm{min}$ ) extinction sessions in a manner not contingent upon lever pressing. Akin to Experiment 1, the lever was retracted for $20 \mathrm{~s}$ after each lever press; lever retraction, however, was not related to IL inhibition. Rats received the average number of laser presentations \pm the SD of the number of lever presses by rats in the contingent experiment. These laser presentations were $20 \mathrm{~s}$ in duration and were presented randomly throughout the session. For Experiment $1 \mathrm{c}$, the empty vector (AAV5-CaMKII $\alpha$-eYFP) was injected into the IL (i.e., a no-opsin, lightalone control group). Rats received illumination immediately after unreinforced lever presses during the five $30 \mathrm{~min}$ extinction sessions. Sham controls for Experiments $1 \mathrm{~b}$ and $1 \mathrm{c}$ were connected to the optical fiber leashes, but no illumination was provided. All rats underwent reinstatements as described for Experiment la.

\section{Experiment 2: IL inhibition after unreinforced lever presses after food self-administration}

This experiment investigated whether IL inhibition immediately after unreinforced lever presses alters extinction for a food self-administration task. During the food-primed reinstatement, a $45 \mathrm{mg}$ pellet was passively delivered every $2 \mathrm{~min}$ for the first $30 \mathrm{~min}$ of the session, but active lever presses had no consequence. All other procedures were the same as described for Experiment 1 with the exception that no catheters were im- 
planted and, during self-administration, active lever presses resulted in the delivery of a $45 \mathrm{mg}$ food reward (same food pellets described above) instead of a cocaine infusion.

\section{Experiment 3: PL inhibition after} unreinforced lever presses

To rule out the possibility that virus and optics targeted to the IL also affected activity in the PL and that PL inhibition could be responsible for the results obtained in Experiment 1, Experiment 3 investigated whether optical inhibition of the PL pyramidal cells immediately after unreinforced lever presses affected ongoing lever pressing, the retention of extinction, or subsequent reinstatement of cocaine seeking. Therefore, virus injection and optical fiber implantation were targeted at the PL. Otherwise, the procedures were identical to those of Experiment la.

\section{Experiment 4: IL inhibition after lever presses during the reinstatement of cocaine seeking}

Based on our results from Experiment 1, we decided to investigate whether temporally precise IL inhibition after each lever press during reinstatement would potentiate cocaine seeking during the reinstatement session. In this experiment, rats underwent cocaine self-administration as described for Experiment 1. Rats then underwent at least $8 \mathrm{~d}$ of full-length $(2 \mathrm{~h})$ extinction sessions, during which active lever presses resulted in the retraction of the lever, but not the delivery of cocaine or its associated cues. Criteria for undergoing reinstatement sessions were the same as described for Experiment 1. For Experiment 4a, cued and cocaine-primed reinstatement sessions were as described for Experiment 1 but, during these sessions, active lever presses also resulted in $20 \mathrm{~s}$ of optical inhibition. However, in contrast to the prior experiments, Experiment 4 was conducted in a within-subjects manner. Each rat underwent each form of reinstatement twice, in a counterbalanced manner with regard to laser versus sham, but in the same order (i.e., cued, followed by cocaine-primed).

To determine whether the $20 \mathrm{~s}$ immediately after a lever press was the temporal window of importance during cued reinstatement, Experiment $4 \mathrm{~b}$ exposed an additional group of rats to optical IL inhibition not contingent upon lever pressing during cued reinstatement, akin to the procedures used in Experiment 1b. Rats received the average number of laser applications \pm the SD of the number of lever presses executed by rats in the laser group from Experiment $4 \mathrm{a}$. As with Experiment 1b, the levers were retracted after an active press, but lever retraction was unrelated to IL inhibition. This experiment followed a within-subjects design such that each rat received both sham and laser manipulations in a counterbalanced manner.

\section{Histological analysis}

Rats were overdosed with sodium pentobarbital (100 mg/kg, i.p.) and transcardially perfused with $60 \mathrm{ml}$ of PBS, pH 7.4, followed by $60 \mathrm{ml}$ of $4 \%$ paraformaldehyde in PBS. Brains were stored in room temperature PBS for 24-48 h before sectioning. Brains were coronally sectioned (75 $\mu \mathrm{m})$ and either mounted on gelatin-coated slides and stained with cresyl violet or stored in antifreeze in a $-20^{\circ}$ freezer for later immunohistochemical analysis. Optical fiber termination points were visualized on cresyl violet-stained sections under a light microscrope according to the Paxinos and Watson atlas. Immunohistochemical analysis was conducted to verify virus expression. Briefly, sections were incubated for $48-72 \mathrm{~h}$ in anti-GFP primary antibody solution (PBS, 2\% goat serum,
0.4\% Triton X-100, rabbit 1:20,000 primary antibody; Abcam), followed by $1 \mathrm{~h}$ incubation in a biotinylated anti-rabbit secondary antibody solution (KPBS, $0.3 \%$ Triton X; goat, 1:200; Vector Laboratories). Sections were incubated in an $\mathrm{ABC}$ kit (Vector Laboratories) for $1 \mathrm{~h}$ before being developed in diaminobenzidine for 3-10 min. Tissue sections were mounted on gelatin-coated slides and dehydrated with reverse alcohol washes before coverslipping. EYFP expression was visualized with a light microscope. Rats with misplaced virus expression or optic probes were excluded from analysis.

\section{Statistical analysis}

For Experiments 1, 2, and 3, active lever presses during shortened extinction sessions were analyzed using a two-way ANOVA with day as the repeated-measures variable in Prism software (GraphPad Software). Active lever presses during the $7 \mathrm{~d}$ of full-length extinction sessions were used as the index of retention for the shortened extinction session and were analyzed using a three-parameter nonlinear mixed effect model in $\mathrm{R}$ (R Core Team, 2012). Although a two-way repeated-measures ANOVA is the conventional way to analyze extinction data, newer, nonlinear, mixed-effects approaches provide superior methods for characterizing and analyzing extinction data, which are better characterized as after an asymptotic exponential function (Pinheiro and Bates, 2000). This mixed-effects approach fits the asymptotic exponential function to all rats' data and, moreover, allows for analysis of group differences around three parameters. Specifically, fixed effects were estimated for the asymptote, the difference between the starting and ending levels of active lever presses during the extinction training, and the rate of extinction learning 


\section{$\underline{\text { L contingent inhibition }}$}

A

Experimental timeline

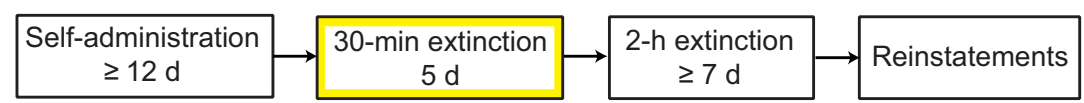

B

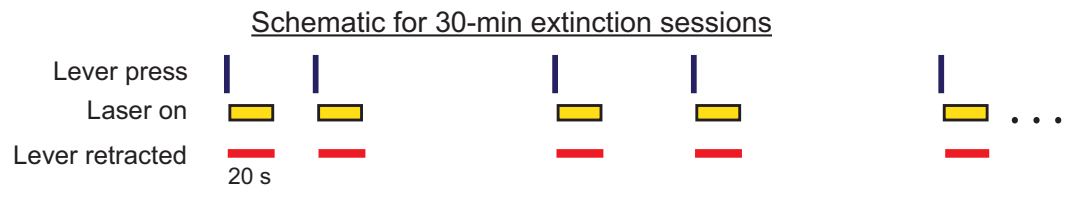

\section{C}

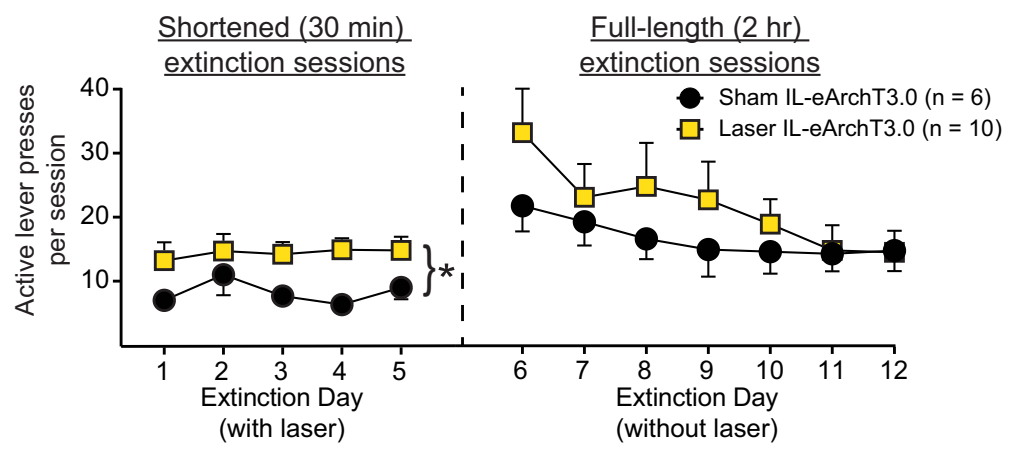

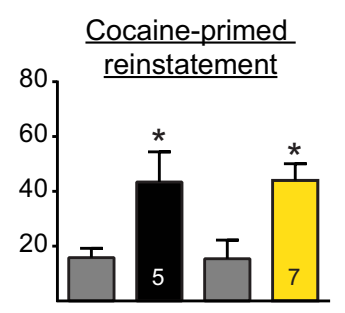

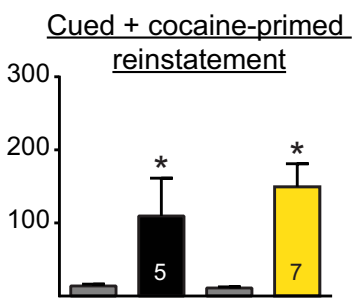

Figure 2. A. Experimental timeline for Experiment 1a, in which optical manipulations occurred during 30 min extinction sessions (yellow box). $\boldsymbol{B}$, Within-session schematic for Experiment 1a. During 30 min extinction sessions, IL pyramidal neurons were optically silenced (yellow rectangles) for $20 \mathrm{~s}$ after unreinforced active lever presses (vertical lines). The active lever was retracted after a lever press and during the period of illumination (red horizontal lines). C, Optical inhibition significantly increased within-session lever pressing during shortened extinction sessions (left) but had no effect on the retention of extinction (right). ${ }^{*} p<0.01$ for sham versus laser. $\boldsymbol{D}$, IL optical inhibition during shortened extinction sessions increased subsequent cued reinstatement, but had no effect on cocaine-primed or cued + cocaine-primed reinstatement. ${ }^{*} p<0.05$ relative to extinction baseline; $\& p<0.01$ relative to sham.

(retention). The maximal random effects structure supported by the data included random intercepts for the asymptote and the difference between the starting and ending levels of active lever presses. Manipulation was examined as a predictor of the retention of extinction. However, because the nonlinear mixed-effects model was too complex to fit the data in the shortened extinction sessions for all experiments and the full-length extinction session in the food experiment, these data were analyzed with two-way repeated-measures ANOVA. Therefore, to be consistent, all full-length extinction sessions were analyzed with the twoway ANOVA in addition to the nonlinear mixed-effects analysis.

For the reinstatement tests in Experiments 1-3, active lever pressing during the extinction baseline (an average of the $2 \mathrm{~d}$ immediately preceding the reinstatement) and reinstatement tests was examined using a two-way repeated-measures ANOVA with day (extinction vs reinstatement) as a within-subjects variable and manipulation (sham vs laser) as a between-subjects variable. In Experiment 1b, the percentage of laser-on periods during which rats pressed the lever was compared between sham and laser groups using an unpaired $t$ test. Reinstatement tests in Experiment 4 were analyzed using one-way repeated-measures ANOVA. Hol$\mathrm{m}$-Sidak's multiple-comparisons test was used for all post hoc analyses. In Experiment 4, the cumulative frequency distributions were compared between sham and laser groups using the Kolmogorov-Smirnov test with MATLAB (The MathWorks). $p<0.05$ was considered significant. Values are graphed as mean \pm SEM. Inactive lever presses were also analyzed but, to streamline the reporting of results, inactive lever presses are addressed only in those experiments in which statistically significant differences based on group condition were observed. In some cases, rats' lever pressing data during a specific reinstatement test was excluded from the analysis for that test due to being statistical outliers within that specific reinstatement test (as defined by being 2 SDs beyond the mean, $n=3$; noted in the Results where this occurs). In addition, some rats that successfully completed extinction training and/or some reinstatement tests were unable to complete all reinstatement tests due to illness and death $(n=4)$ or to failure to reextinguish after the first reinstatement $(n=1)$, leading to a decrease in the $n$ in some experiments.

\section{Results}

Figure $1 A$ shows a schematic of fiber-optic termination points and areas of illumination for fiber optics aimed at the IL (Fig. 1, left) and the PL (Fig. 1, right). Figure $1 B$ shows representative histological images, including immunohistochemical staining (Fig. 1B, left), cresyl violet staining (Fig. $1 B$, middle), and fluorescent imaging (Fig. $1 B$, right). Figure $1 C$ shows electrophysiological confirmation of functional eArchT3.0 expression in the IL during whole-cell recordings. Illumination with $561 \mathrm{~nm}$ light provided a robust outward current for the duration of the illumination. As shown in Figure 1D, such illumination also prevented action potentials induced by injected current.

\section{Lever press-contingent IL inhibition increases cocaine seeking during extinction and enhances subsequent cued reinstatement}

To determine whether IL pyramidal neuron activity immediately after unreinforced lever presses contributes to the extinction of cocaineseeking behavior, rats underwent 5 shortened (30 $\mathrm{min})$ extinction sessions during which IL pyramidal neurons were inhibited optically for $20 \mathrm{~s}$ immediately after lever presses. Figure $2 A$ shows the experimental timeline and Figure $2 B$ shows a within-session schematic for Experiment 1a. Figure 2C, left, shows active lever presses during the shortened extinction sessions. Optical inhibition of IL pyramidal neurons increased ongoing active lever pressing (main effect of manipulation, $F_{(1,14)}=$ 9.95, $p=0.007)$. No change in active lever presses was observed across days $\left(F_{(4,56)}=0.51, p=0.73\right)$ and no interaction was present $\left(F_{(4,56)}=0.32, p=0.86\right)$. Because the active lever was retracted during the period of illumination, the increase in lever pressing could not be due to the acute effects of IL inhibition on ongoing behavior. Nonetheless, we considered the possibility that the increased lever pressing occurred immediately after the termination of the inhibition. Therefore, we analyzed lever presses occurring during the $10 \mathrm{~s}$ immediately after laser termination. There were no between-group differences in the percentage of lever presses that occurred during this time window $\left(t_{(14)}=1.27, p=0.23\right)$. Figure $2 C$, right, shows the active lever 
pressing during the full-length (2 h) extinction sessions when no inhibition was given. Analyses of the full-length extinction sessions indicated that IL inhibition given during the shortened extinction sessions had no effect on the retention of extinction learning. A two-way ANOVA revealed no between-group differences $\left(F_{(1,14)}=0.62, p=0.45\right)$, a significant effect of day $\left(F_{(6,84)}=5.13, p=0.0002\right)$, and no interaction $\left(F_{(6,84)}=1.13, p=0.36\right)$. The three-parameter nonlinear mixedeffects analysis similarly revealed no between-group differences in lever pressing $\left(t_{(93)}=1.15, p=0.12\right)$. There was a significant change in active lever pressing across the $7 \mathrm{~d}$ of full-length extinction sessions, reflecting extinction learning across days $\left(t_{(93)}=-3.49, p=0.0043\right)$.

Figure $2 D$ shows the active lever pressing during cued, cocaine-primed, and cued + cocaine-primed reinstatement, respectively, of those rats that had previously received IL pyramidal neuron inhibition. A two-way ANOVA of the cued reinstatement data revealed a significant effect of reinstatement $\left(F_{(1,13)}=35.13\right.$, $p<0.0001)$, a significant effect of manipulation $\left(F_{(1,13)}=5.01, p<0.05\right)$, and a strong trend for a significant interaction $\left(F_{(1,13)}=4.57, p=0.05\right)$. Post hoc tests confirmed that those rats that had previously received optical inhibition during the shortened extinction sessions had significantly higher active lever pressing during cued reinstatement relative to sham controls $(p<0.01)$.

For cocaine-primed reinstatement, a two-way ANOVA revealed a strong trend for an effect of reinstatement $\left(F_{(1,11)}=4.72\right.$, $p=0.05)$, but no effect of manipulation $\left(F_{(1,11)}=0.56, p=0.47\right)$ and no interaction $\left(F_{(1,11)}=0.60, p=0.46\right)$. However, inspection of the data revealed a statistical outlier in the laser group. When the outlier was excluded, rats showed significant reinstatement (Fig. $\left.2 D, F_{(1,10)}=25.02, p=0.0005\right)$, but there was no effect of manipulation $\left(F_{(1,10)}=0.00031, p=0.99\right)$ and no interaction $\left(F_{(1,10)}=0.0075, p=0.93\right)$. With the outlier removed, post hoc tests indicated that both sham and laser groups significantly reinstated relative to extinction baseline $(p<0.05)$. When all rats were included in the cocaine-primed reinstatement analysis, rats in the sham group completed $43.4 \pm 11.00$ active lever presses and rats in the laser group completed $73.88 \pm 30.34$ active lever presses. When the outlier was excluded from the laser group, rats in the laser group executed $44.00 \pm 6.11$ active lever presses during the reinstatement session.

For the cue + cocaine-primed reinstatement, a two-way ANOVA of active lever presses revealed a significant effect of reinstatement $\left(F_{(1,11)}=9.72, p=0.0098\right)$, but no effect of manipulation $\left(F_{(1,11)}=1.12, p=0.44\right)$ and no interaction $\left(F_{(1,11)}=\right.$ $1.23, p=0.29)$. As with the cocaine-primed reinstatement, inspection of the data revealed a statistical outlier in the laser group. When this outlier was excluded from the analysis, rats significantly reinstated (Fig. $2 D, F_{(1,10)}=18.34, p=0.0016$ ), but no difference was apparent between groups $\left(F_{(1,10)}=0.39, p=0.54\right)$

\section{$\underline{\mathrm{IL} \text { non-contingent inhibition }}$}

Schematic for 30-min extinction sessions

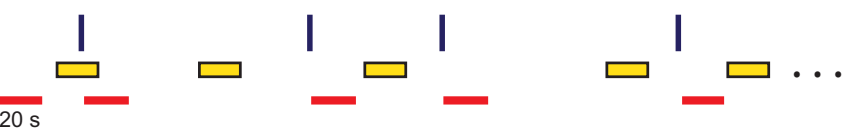

Shortened (30 min) Full-length (2 hr) extinction sessions $\quad$ extinction sessions

Sham IL-eArchT3.0 $(n=8)$

$\square$ Laser IL-eArchT3.0 ( $(\mathrm{n}=8)$

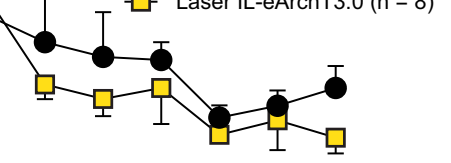

$\begin{array}{lllllllllllll}1 & 2 & 3 & 4 & 5 & & 6 & 7 & 8 & 9 & 10 & 11 & 12\end{array}$

$\begin{array}{cc}\text { Extinction Day } & \text { Extinction Day } \\ \text { (with laser) } & \text { (without laser) }\end{array}$

Cued + cocaine-primed reinstatement

Cocaine-primed reinstatement
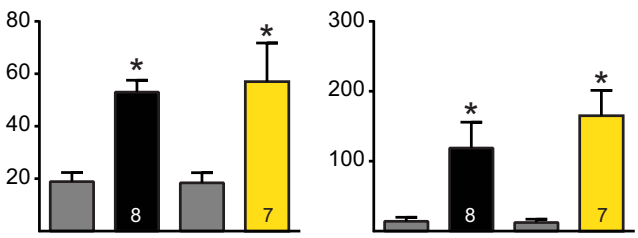

Figure 3. A, Within-session schematic for Experiment $1 \mathrm{~b}$ with noncontingent optical inhibition of IL pyramidal neurons. Illumination was provided in a random manner (i.e., unrelated to the lever presses) throughout the shortened extinction sessions. $\boldsymbol{B}$ Noncontingent optical inhibition of the IL had no effect on within-session lever pressing during shortened extinction sessions (left) or on the retention of extinction learning (right). C, Noncontingent optical inhibition during extinction had no effect on the reinstatement of cocaine-seeking behavior. ${ }^{*} p<0.01$ relative to extinction baseline.

and no interaction was observed $\left(F_{(1,10)}=0.61, p=0.45\right)$. With the exclusion of the outlier, rats in both sham and laser groups showed significant reinstatement $(p<0.05)$. When all rats were included in the cue + cocaine-primed reinstatement analysis, rats in the sham group completed $109.60 \pm 51.88$ active lever presses and rats in the laser group completed $213.60 \pm 69.43$ active lever presses. When the outlier was excluded from the laser group, the rats in the laser group executed $149.70 \pm 31.32$ active lever presses during the reinstatement session.

For inactive lever presses during cued + cocaine-primed reinstatement, the two-way ANOVA revealed a significant interaction $\left(F_{(1,10)}=6.01, p=0.034\right)$. This effect appeared to be driven by a marginally significant difference in the extinction baseline between the sham and laser groups, in which the sham group had more inactive lever presses compared with the laser group $(p<0.1)$.

For Experiment 1b, we investigated whether optical inhibition of IL pyramidal neurons given in a manner unrelated to active lever pressing (i.e., noncontingent inhibition) during the shortened extinction sessions would produce the same results as observed for Experiment 1a. Figure $3 A$ shows a within-session schematic for Experiment 1b. Figure $3 B$ shows the active lever presses during the shortened extinction (Fig. 3, left) and fulllength extinction session (Fig. 3, right) for both groups. Noncontingent optical inhibition of IL pyramidal neurons had no effect on ongoing active lever pressing during the shortened sessions $\left(F_{(1,14)}=0.28, p=0.60\right)$, but there was a significant effect of time $\left(F_{(4,56)}=4.13, p=0.0053\right)$, reflecting extinction learning across days. No interaction was observed $\left(F_{(4,56)}=0.85, p=0.50\right)$. 


\section{$\underline{\text { IL eYFP illumination alone }}$}

A

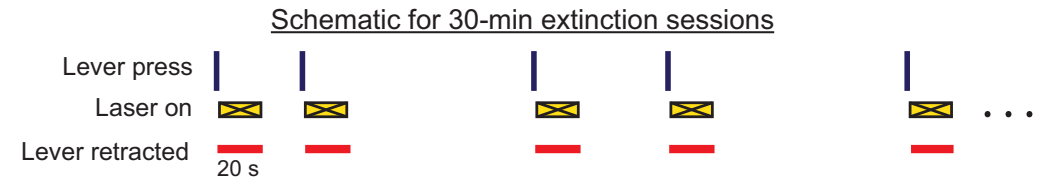

B

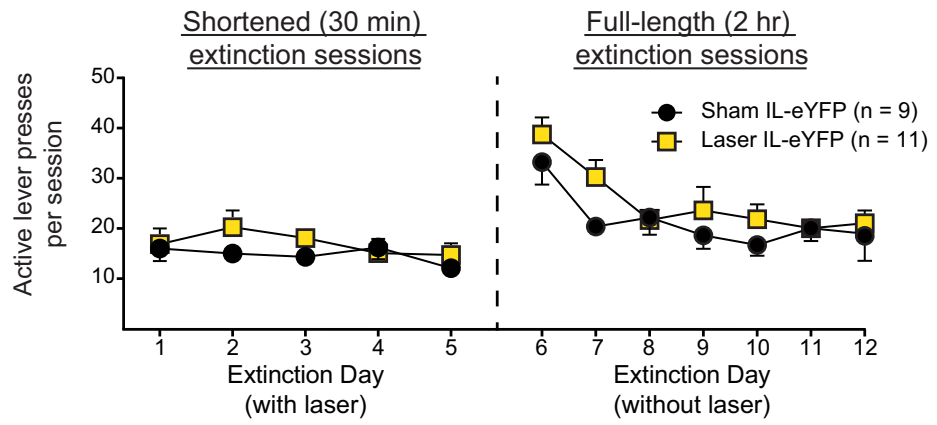

C

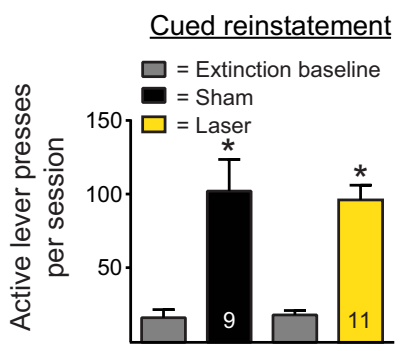

Cued + cocaine-primed reinstatement reinstatement

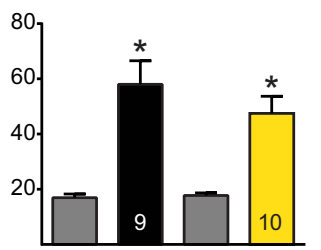

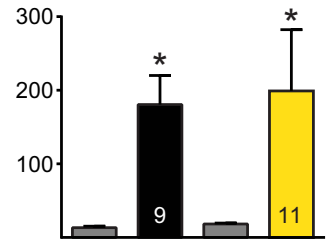

Figure 4. $\quad \boldsymbol{A}$, Within-session schematic for Experiment $1 c$, in which illumination was given in a manner contingent upon lever pressing in rats expressing eYFP, but not eArchT3.0 in IL pyramidal cells (i.e., a no-opsin, illumination-alone control, shown as an " $X$ " during laser on epochs). $\boldsymbol{B}$, Illumination had no effect on within-session lever pressing during shortened extinction sessions (left) or the retention of extinction learning (right). C, Illumination in rats expressing eYFP had no effect on the subsequent reinstatement of cocaine seeking. ${ }^{*} p<0.01$ relative to extinction baseline.

Because lever retraction was linked to lever pressing rather than laser-on periods, we analyzed lever pressing during laser-on periods. Rats in the laser group did not press more during laser-on periods than rats in the sham group $\left(t_{(13)}=1.27, p=0.22\right)$. Analyses of the full-length extinction sessions indicated that IL inhibition given during the shortened extinction sessions had no effect on the retention of extinction learning. A two-way repeated-measures ANOVA revealed no main effect of manipulation on active lever pressing $\left(F_{(1,15)}=1.66, p=0.22\right)$, a main effect of day $\left(F_{(6,90)}=4.96, p=0.0002\right)$, and no interaction $\left(F_{(6,90)}=0.19, p=0.98\right)$. Similarly, the three-parameter nonlinear mixed-effects analysis revealed that noncontingent optical inhibition had no effect on the retention of extinction learning, as assessed by the rate of learning during the subsequent full-length extinction sessions $\left(t_{(93)}=-1.01, p=0.31\right)$. A significant change in active lever pressing was observed across days of full-length extinction sessions $\left(t_{(93)}=-3.73, p=0.0003\right)$.

Figure $3 C$ shows the active lever presses for Experiment $1 \mathrm{~b}$ for cued reinstatement, cocaine-primed reinstatement, and cued + cocaine-primed reinstatement for rats that had previously received noncontingent IL inhibition during the shortened extinction sessions. In all three cases, rats significantly reinstated their active lever pressing, as assessed by main effects of reinstatement $\left(F_{(1,14)}=36.28, p<0.0001 ; F_{(1,13)}=\right.$ $24.42, p=0.0003$; and $F_{(1,13)}=27.04, p=0.0002$, respectively). However, optical inhibition during extinction had no effect on subsequent cued, cocaine-primed, or cued + cocaine-primed reinstatement, as indicated by the lack of ef-

fect of manipulation $\left(F_{(1,14)}=0.24, p=\right.$ $0.63 ; F_{(1,13)}=0.05, p=0.81$; and $\left(F_{(1,13)}=1.10, p=0.31\right.$, respectively) and by the lack of a significant interaction during any of the reinstatement tests $\left(F_{(1,14)}=0.24, p=0.63 ; F_{(1,13)}=\right.$ $0.091, p=0.77$; and $F_{(1,13)}=1.32, p=$ 0.27 , respectively). Therefore, noncontingent IL inhibition during shortened extinction sessions had no effect on extinction behavior during the shortened sessions, the retention of the extinction learning, or the subsequent reinstatement of cocaine seeking.

In control Experiment 1c, CaMKII $\alpha$ eYFP alone (no opsin) was expressed in IL pyramidal cells. As with Experiment 1a, illumination was given for $20 \mathrm{~s}$ immediately after unreinforced active lever presses during shortened extinction sessions. Figure $4 A$ shows the within-session schematic for this experiment. Figure $4 B$ shows the active lever presses during the shortened and full-length extinction sessions. A two-way ANOVA for the shortened extinction sessions revealed no main effect of manipulation on active lever pressing $\left(F_{(1,18)}=1.38, p=0.26\right)$, no effect of day on active lever pressing $\left(F_{(4,72)}=0.93, p=0.45\right)$, and no interaction $\left(F_{(4,72)}=0.60, p=0.66\right)$. A two-way repeated-measures ANOVA of the fulllength extinction sessions revealed no main effect of manipulation on active lever pressing $\left(F_{(1,18)}=2.55, p=0.13\right)$, a significant effect of day on active lever pressing $\left(F_{(6,108)}=7.56\right.$, $p<0.0001)$, and no interaction $\left(F_{(6,108)}=0.50, p=0.81\right)$. The three-parameter nonlinear mixed-effects analysis of the same data showed that illumination had no effect on the retention of extinction learning, as assessed by the rate of extinction learning $\left.t_{(117)}=0.90, p=0.37\right)$. There was a statistically significant overall decrease in active lever pressing across the full-length extinction sessions $\left(t_{(117)}=-6.04, p<0.0001\right)$.

Figure $4 C$ shows the active lever pressing during the reinstatement tests for the no-opsin illumination-alone experiment. One rat from the laser group was excluded from the cocaine-primed reinstatement as a statistical outlier. Two-way ANOVAs revealed that rats significantly reinstated, as demonstrated by a significant main effect of reinstatement for cued, cocaine-primed, and cue + cocaine-primed reinstatements $\left(F_{(1,18)}=53.52, p<0.0001\right.$; $F_{(1,17)}=51.83, p<0.0001 ;$ and $F_{(1,18)}=12.21, p=0.0026$, respectively). However, there was no significant main effect of manipulation for any of the reinstatement tests $\left(F_{(1,18)}=0.032\right.$, $p=0.86 ; F_{(1,17)}=0.75, p=0.40$; and $F_{(1,18)}=0.056, p=0.82$, respectively) or significant interaction $\left(F_{(1,18)}=0.12, p=\right.$ $0.73 ; F_{(1,17)}=1.32, p=0.27$; and $F_{(1,18)}=0.018, p=0.89$, respectively).

Lever press-contingent IL inhibition has no effect on food seeking during extinction or subsequent reinstatement

Experiment 2 repeated the procedures of Experiment 1a with a food reward rather than cocaine. Figure $5 A$ shows a withinsession schematic for this experiment. Figure $5 B$ shows the active 
lever pressing during the shortened and full-length extinction sessions. A two-way ANOVA revealed no significant main effect of manipulation on active lever presses during the shortened extinction sessions $\left(F_{(1,14)}=0.0022, p=0.96\right)$, indicating that optical inhibition of IL pyramidal neurons had no effect on lever pressing. A main effect of day was present $\left(F_{(4,56)}=10.88, p<0.0001\right)$, but there was no significant interaction $\left(F_{(4,56)}=\right.$ $0.51, p=0.73$ ). Analyses of the full-length extinction sessions indicated that IL inhibition given during the shortened extinction sessions had no effect on the retention of extinction learning. A twoway ANOVA of full-length extinction sessions revealed no effect of prior manipulation $\left(F_{(1,14)}=0.087, p=0.77\right)$ and no interaction $\left(F_{(6,84)}=1.51, p=\right.$ $0.18)$. There was a significant effect of days, reflecting an overall decrease in active lever pressing across the full-length extinction sessions $\left(F_{(6,84)}=15.31, p<\right.$ $0.0001)$.

Figure $5 C$ shows the results for the reinstatement sessions (cued, food-primed, and cue + food-primed, respectively) for those rats that underwent food self-administration. Two-way ANOVAs revealed significant main effects of reinstatement for cued, food-primed, and cued + food-primed reinstatement $\left(F_{(1,14)}=20.85, p=0.0004 ; F_{(1,14)}=\right.$ $19.34, p=0.0006$; and $F_{(1,14)}=13.45, p=0.0025$, respectively). However, such ANOVAs revealed no main effect of manipulation $\left(F_{(1,14)}=0.0023, p=0.96 ; F_{(1,14)}=0.39, p=\right.$ 0.54 ; and $F_{(1,14)}=0.015, p=0.90$, respectively) or significant interaction in any of the reinstatement tests $\left(_{(1,14)}=0.01\right.$, $p=0.92 ; F_{(1,14)}=0.46, p=0.51$; and $F_{(1,14)}=0.016, p=0.90$, respectively).

\section{Lever press-contingent PL inhibition decreases cocaine seeking during extinction}

To rule out the possibility that virus and optics targeted to the IL also affected activity in the PL, Experiment 3 investigated whether optical inhibition of the PL pyramidal cells immediately after unreinforced lever presses affected ongoing lever pressing and the retention of extinction learning using the same procedures from Experiment 1a. Figure $6 A$ shows a within-session schematic for this experiment. Figure $6 B$ shows the active lever presses during the shortened and full-length extinction sessions. A two-way ANOVA of active lever pressing during the shortened sessions revealed a significant main effect of manipulation $\left(F_{(1,12)}=9.7\right.$, $p=0.0089)$. No change in lever pressing across days was observed $\left(F_{(4,48)}=0.64, p=0.64\right)$, but a marginally significant interaction was present $\left(F_{(4,48)}=2.51, p=0.054\right)$. Optical inhibition of PL pyramidal cells also significantly decreased inactive lever presses during the shortened extinction sessions $\left(F_{(1,12)}=6.75, p=\right.$ 0.023 , data not shown). Therefore, PL inhibition immediately after an unreinforced lever press significantly decreased overall lever pressing and this was most likely driven by the decrease observed on days 1 and 2. Analyses of the lever pressing during

\section{$\underline{I L}$ inhibition - food seeking}

Schematic for $30-$ min extinction sessions

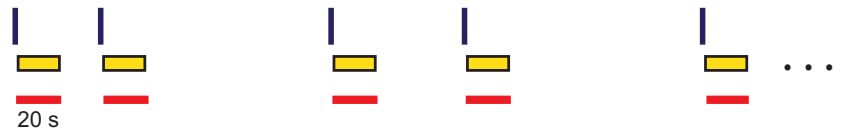

Shortened (30 min) $\quad$ Full-length $(2 \mathrm{hr})$ extinction sessions $\quad$ extinction sessions

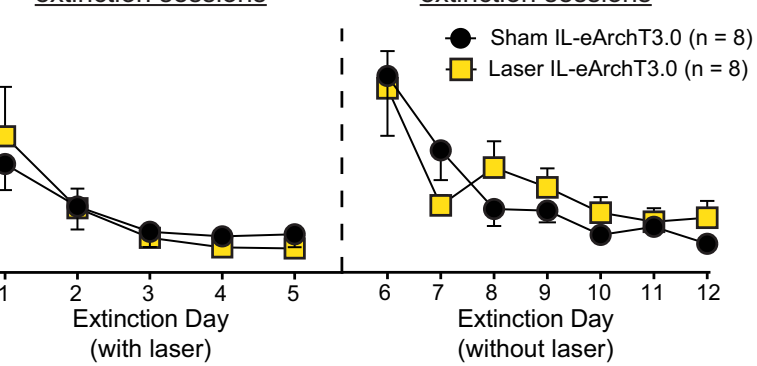

Food-primed reinstatement

$\underline{\text { Cued }+ \text { food-primed }}$ reinstatement
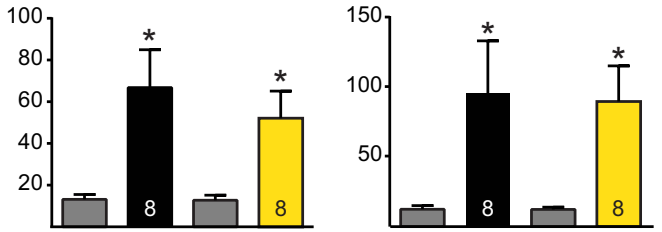

Figure 5. A, Within-session schematic for Experiment 2, in which IL pyramidal neurons were inhibited optically during extincforced lever press during the five shortened extinction sessions. $\boldsymbol{B}$, Optical inhibition had no effect on within-session lever pressing during shortened extinction sessions (left) or on the retention of extinction learning (right). C, IL optical inhibition during extinction had no effect on the subsequent reinstatement of food-seeking behavior. ${ }^{*} p<0.01$ relative to extinction baseline.

the full-length sessions, however, revealed that optical inhibition given during the shortened extinction sessions had no effect on the retention of extinction learning during the full-length extinction sessions. A two-way ANOVA revealed no main effect of group $\left(F_{(1,12)}=0.17, p=0.69\right)$, a significant main effect of day $\left(F_{(6,72)}=9.78, p<0.0001\right)$, and no interaction $\left(F_{(6,72)}=1.29\right.$, $p=0.27)$. The three-parameter nonlinear mixed-effects analysis revealed no between-group differences in active lever pressing $\left(t_{(81)}=-0.53, p=0.59\right)$. A significant difference in overall active lever pressing across days was present, reflecting extinction learning across days $\left(t_{(81)}=-4.80, p<0.0001\right)$.

Figure $6 C$ shows active lever pressing during the cued, cocaine-primed, and cued + cocaine-primed reinstatement tests for those rats that had previously received PL-pyramidal neuron inhibition. One rat from the sham group failed to reextinguish after cued reinstatement and one rat from the laser group was a statistical outlier for the cocaine-primed reinstatement test, leading to the different $n$ 's for the reinstatement analyses. Two-way ANOVAs revealed that rats significantly reinstated cocaine seeking, as evidenced by significant main effects of reinstatement in all cases $\left(F_{(1,12)}=22.58, p=0.0005 ; F_{(1,10)}=12.65, p=0.0052\right.$; and $F_{(1,11)}=34.16, p=0.0001$, respectively). However, the ANOVAs did not reveal any significant effects of manipulation $\left(F_{(1,12)}=0.50, p=0.49 ; F_{(1,10)}=0.0038, p=0.95\right.$; and $F_{(1,11)}=$ $0.92, p=0.74$, respectively) or significant interactions for any of the reinstatement tests $\left(F_{(1,12)}=1.08, p=0.32 ; F_{(1,10)}=0.039\right.$, $p=0.85$; and $F_{(1,11)}=0.05, p=0.82$, respectively). For the inactive lever presses, a two-way ANOVA revealed a significant effect of manipulation during cocaine-primed reinstatement 
A

\section{PL contingent inhibition}

Schematic for 30-min extinction sessions

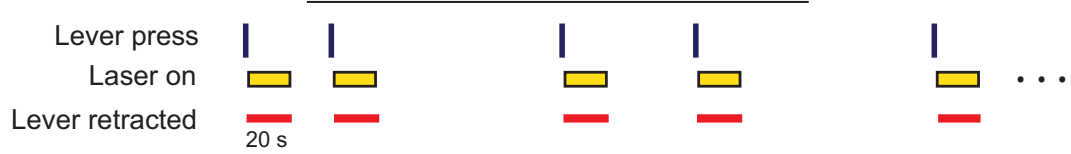

B

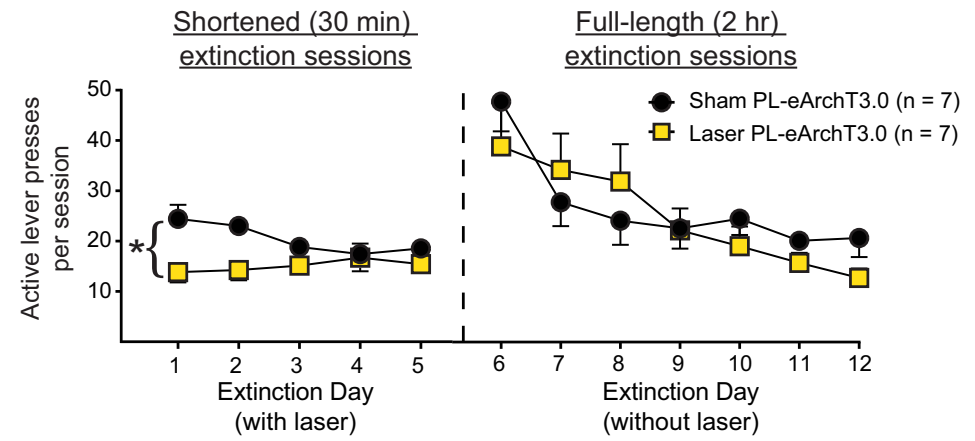

\section{C}

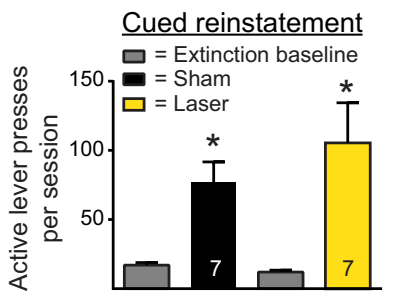

$\underline{\text { Cued }+ \text { cocaine-primed }}$

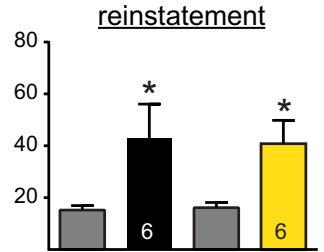
reinstatement

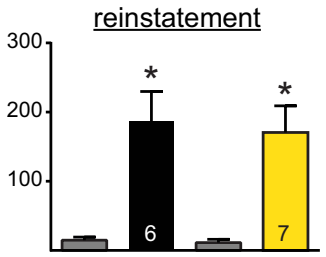

Figure 6. A, Within-session schematic for Experiment 3 , in which PL pyramidal neurons were optically silenced during 30 min extinction sessions. As in the experiment shown in Figure 2 , illumination was provided for $20 \mathrm{~s}$ after each unreinforced lever press during the five shortened extinction sessions after cocaine self-administration. $\boldsymbol{B}, \mathrm{PL}$ inhibition decreased within-session lever pressing during the shortened extinction sessions (left), but had no effect on the retention of extinction learning as assessed by the full-length extinction sessions (right). ${ }^{*} p<0.01$ for sham versus laser. C, PL optical inhibition during extinction had no effect on the subsequent reinstatement of cocaine seeking. ${ }^{*} p<0.01$ relative to extinction baseline.

$\left(F_{(1,10)}=5.61, p=0.039\right)$. Inspection of the cocaine-primed reinstatement data suggest that these effects are due to marginally decreased lever pressing in laser-treated rats relative to sham rats during reinstatement $(p<0.1$, data not shown).

Lever press-contingent IL inhibition increases cocaine seeking during cued reinstatement

Based on the results of Experiment 1, we considered whether optically inhibiting IL pyramidal neurons in a similar manner as part of a reinstatement test would alter active lever pressing during the reinstatement. Therefore, in Experiment 4a, IL pyramidal neurons were inhibited optically for $20 \mathrm{~s}$ immediately after active lever presses during cued and cocaine-primed reinstatement tests, but not during extinction sessions. Figure $7 A$ shows the experimental timeline and Figure $7 B$ shows the within-session schematic for this experiment. Figure $7 C$ shows the active lever presses from the cued reinstatement experiments. A one-way repeated-measures ANOVA indicated a significant main effect during cued reinstatement $\left(F_{(2,24)}=10.64, p=0.0037\right)$. Post hoc analyses revealed that, in both sham and laser conditions, rats significantly increased active lever pressing relative to extinction baseline ( $p<0.05$ in both cases). However, those rats receiving optical inhibition during the session had higher active lever presses than their sham counterparts $(p<0.05)$. Because this was a longer session with more active lever pressing than the shortened extinction sessions (as in Experiment 1a), we also investigated whether there was a shift in when, during the session, the rats receiving inhibition engaged in active lever pressing. Figure $7 D$ shows a cumulative frequency curve for the proportion of active lever presses across the $2 \mathrm{~h}$ cued reinstatement session. There was no significant difference in the frequency curve $(p=0.35)$, indicating that those rats receiving IL inhibition had an overall increase in their active lever pressing across the entire session. Figure $7 E$ shows the active lever presses during the cocaine-primed reinstatement. A one-way repeated-measures ANOVA revealed a significant main effect $\left(F_{(2,24)}=13.52, p=0.0007\right)$. Post hoc analyses revealed that, in both sham and laser conditions, rats significantly increased active lever pressing relative to extinction baseline ( $p<0.05$ in both cases), but that the two groups did not differ in lever pressing $(p>0.05)$.

Experiment $4 \mathrm{~b}$ applied noncontingent optical inhibition during reinstatement sessions to examine whether neural firing immediately after active lever presses was responsible for the enhanced cued reinstatement observed in Experiment 4a. A one-way repeated-measures ANOVA revealed a significant main effect $\left(F_{(2,14)}=\right.$ 6.17, $p=0.012$ ). Post hoc tests indicated that the sham group significantly reinstated relative to the extinction baseline $(p<0.05)$ and that the laser group had a trend toward a significant reinstatement relative to the extinction baseline $(p<$ 0.1 ). However, critically, there was no difference between the sham and laser groups $(p>0.05)$.

\section{Discussion}

The present work found that IL pyramidal neuron inhibition triggered by an unreinforced lever press impaired the extinction of cocaine seeking. This impairment was reflected in a withinsession increase in lever pressing during the sessions in which optical inhibition occurred. Altering the early extinction learning also had consequences for later cocaine-seeking behavior because those rats that had received contingent IL pyramidal neuron inhibition displayed greater levels of cued reinstatement. The failure to observe similar effects when IL pyramidal cells were inhibited in a pseudorandom, noncontingent manner (i.e., in a manner unrelated to the lever pressing) suggests the critical nature of the period after unreinforced lever presses in the encoding of the new associations involved in extinction learning for cocaine seeking.

\section{Temporally restricted window of IL activity contributes to} extinction learning after cocaine self-administration Early work identifying a critical role for the IL in the inhibition of cocaine seeking found that IL inactivation via intra-IL administration of GABAergic agonists induces cocaine seeking in rats that have undergone self-administration and extinction training $(\mathrm{Pe}-$ ters et al., 2008). Similarly, later work found that activation of the IL or of the IL projections to the nucleus accumbens shell (NAshell) reduces cue-induced cocaine seeking (LaLumiere et al., 2012; Augur et al., 2016, cf., Koya et al., 2009). Recent findings using $6 \mathrm{~h}$ access models combined with an "incubation-ofcraving" paradigm likewise suggest that IL projections to the 
NAshell are specifically involved in suppressing cocaine seeking (Ma et al., 2014). Other work suggests that the IL is involved in extinction learning itself. Pharmacological manipulations of the IL given either before or after each extinction session over the first several days of extinction training alters the retention of the extinction learning for cocaine seeking (LaLumiere et al., 2010; Hafenbreidel et al., 2015). However, manipulations that affect behavior during extinction learning could produce confounds in assessing the retention of such learning. Moreover, these findings do not indicate whether temporally restricted periods of IL activity during extinction learning contribute to such learning.

To address this, the present study used an activity-guided optogenetic approach in which rats' lever pressing controlled optical illumination and thereby provided temporally restricted (20 s) inhibition of IL pyramidal neuron activity during extinction training. Such inhibition immediately after unreinforced lever presses increased lever pressing during the shortened extinction sessions. Because prior work indicates that the IL is also involved in suppressing cocaine seeking (Peters et al., 2008), it is possible that IL inhibition during the first $5 \mathrm{~d}$ of extinction disrupted the normal suppression of cocaine seeking rather than disrupting the encoding of the new contingencies. Careful consideration of the current findings, however, suggests that this is unlikely to account for our results. First, IL pyramidal cell activity was only inhibited when the levers were retracted, enabling activity to return to normal when the opportunity to press the lever was present. Moreover, lever pressing did not increase in the $10 \mathrm{~s}$ after the inhibition ceased. Second, and of particular importance, IL inhibition given in a pseudorandom manner throughout the session (i.e., noncontingent upon the lever press) did not increase lever pressing, strongly arguing that IL inhibition was not simply relieving the suppression of cocaine seeking. Rather, these analyses suggest that IL inhibition immediately after the unreinforced lever press impaired extinction encoding, leading to impaired within-session extinction.

The behavioral data from the $2 \mathrm{~h}$ extinction sessions that served as retention tests provide additional confirmation that IL pyramidal neuron inhibition impaired the encoding of lever press with no reward contingencies. In theory, the observed increase in lever pressing in the first five (shortened) sessions with IL inhibition led to more opportunities to learn the new contingencies between the lever press and lack of reinforcement. As a result, if the rats were engaged in normal encoding of these new contingencies, then the inhibition group should have produced fewer lever presses on the $2 \mathrm{~h}$ retention tests compared with sham control rats. That we did not observe such an effect strongly suggests that the IL inhibi-

\section{IL inhibition during reinstatement}

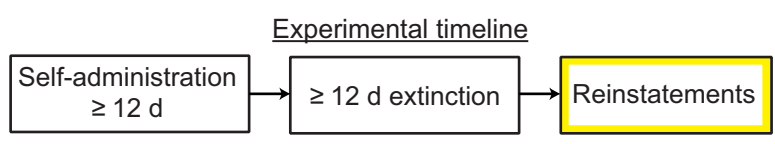

$\underline{\text { Schematic for contingent reinstatement sessions }}$

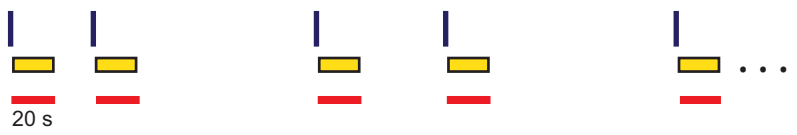

E $\quad$ cocaine-primed
D Cued reinstatement

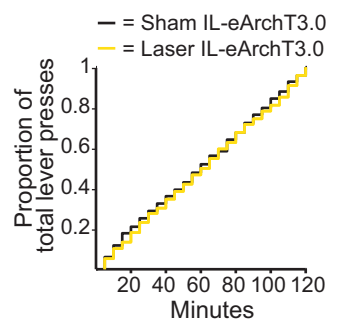

Minutes

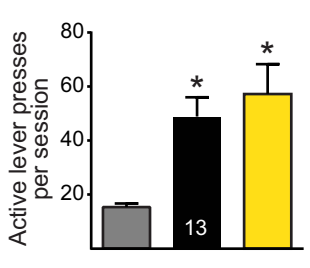

G Noncontingent cued reinstatement

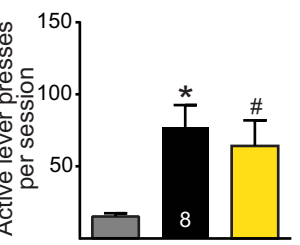

Figure 7. A, Experimental timeline for Experiments $4 \mathrm{a}$ and $4 \mathrm{~b}$, in which optical manipulations of IL pyramidal neurons occurred during reinstatement sessions (yellow box). $\boldsymbol{B}$, Within-session schematic for Experiment 4a. In contrast to prior experiments, rats

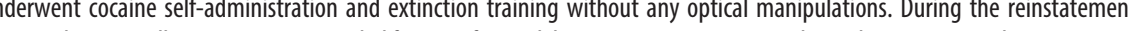
frequency distribution of lever presses during cued reinstatement. $\boldsymbol{E}$, Contingent optical inhibition had no effect on cocaine-primed

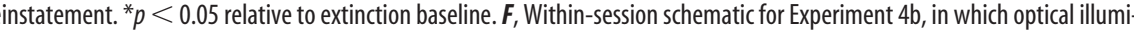
nation was applied noncontingently during cued reinstatement. $\mathbf{G}$, Noncontingent optical inhibition had no effect on lever pressing during cued reinstatement. ${ }^{*} p<0.05$ relative to extinction baseline, $\# p<0.1$ relative to extinction baseline.

tion during the early extinction training impaired the encoding of these new contingencies.

\section{Temporally restricted IL inhibition disrupts encoding during} cued reinstatement

The current work also found increased lever pressing when contingent IL pyramidal neuron inhibition was given during a $2 \mathrm{~h}$ cued reinstatement test, but not during cocaine-induced reinstatement, suggesting that temporally precise inhibition also disrupted the extinction encoding for conditioned reinforcerdriven lever pressing. Consistent with this finding, IL neurons show phasic activity (increases and decreases) in response to instrumental behaviors and cocaine conditioned reinforcers presented during an extinction session in a previous study (West et al., 2014). Although that study provides correlative evidence of lever-press-related IL activity during the extinction of cocaineseeking behavior, such activity was only examined for one extinction session and it is unclear which changes in activity encoded the extinction learning. One possibility is that a population of IL pyramidal neurons encode lack of cocaine receipt by increasing firing after lever pressing. Optically inhibiting such a signal would 
result in impaired extinction learning. Indeed, evidence from tone fear conditioning suggests that IL burst firing after extinction training is important for extinction learning (Burgos-Robles et al., 2007). A second possibility is that inhibitory events may encode reward-related information. Electrophysiological recordings with sucrose seeking suggest that IL neurons primarily show decreases in firing rate after lever presses for the sucrose reward and that the number of such events decreases as rats undergo extinction (Moorman and Aston-Jones, 2015). Therefore, optical inhibition that prevents this extinction-related decrease in inhibitory events may impair extinction learning. A potential caveat in examining food-seeking studies is that the present work found no effects of IL inhibition during the extinction of food seeking. However, it may be that the nature of the food reinforcer (highly palatable food vs standard food pellets) is a critical difference in comparing studies because other work using highly palatable food indicates that neural ensembles in the vmPFC promote the extinction of food-seeking behavior (Warren et al., 2016).

\section{Manipulations during extinction learning affect subsequent cued reinstatement}

Of particular interest, the present experiments found that those rats that had received IL pyramidal neuron inhibition during early extinction training had higher levels of cued reinstatement despite all rats achieving equivalent levels of extinction behavior. However, there was no difference for any reinstatement involving a cocaine prime, suggesting fundamental differences in the neural processes underlying cued and cocaine-primed reinstatement and in agreement with recent results (Augur et al., 2016). It cannot be ruled out, however, that the lack of an effect during cocaine-primed reinstatement was due to the fact that cued reinstatement was presented first in all experiments. Considering that the extinction training itself did not involve cue exposure, the present results suggest that the disrupted encoding of the lever press with no reward contingencies also altered the relationship between the lever press and the conditioned reinforcers (i.e., the cues). Although the mechanism underlying this is unknown, these findings indicate that neurobiological manipulations during early extinction training may have long-lasting consequences on models of relapse.

\section{Consideration of control experiments}

The present work included additional control experiments that help to clarify the findings. The failure to observe any behavioral effects in the illumination-alone control experiments argues against the possibility that any visible illumination that may have escaped from the optical fibers or head cap was responsible for the present results and also that light alone produced neural activity changes responsible for the behavioral effects (Stujenske et al., 2015). In contrast to the cocaine-seeking results, IL pyramidal neuron inhibition with food seeking extinction had no effects on within-session lever pressing, the rate of extinction learning during the full-length extinction sessions, or subsequent reinstatement. These results suggest that the present findings with cocaine seeking are not due to effects on the extinction of instrumental learning alone. Moreover, the results with food seeking indicate that IL pyramidal neuron inhibition immediately after a lever press was not reinforcing on its own. Finally, the current studies also examined the behavioral consequences of optical inhibition of the PL during extinction of cocaine seeking. Consistent with previous work indicating that the PL and its downstream targets promote cocaine-seeking behavior (McFarland et al., 2003; Stefanik et al., 2013; Ma et al., 2014), PL inhibition during the short- ened extinction sessions reduced cocaine seeking during that period. However, this effect appeared to be limited to only the first $2 \mathrm{~d}$ of extinction without altering the retention of the extinction training or subsequent reinstatement tests.

Considering the lack of effects on food seeking in the present study, the issue of the role of the IL in seeking behavior for rewards in general, and especially other drugs of abuse, is particularly salient. As with cocaine, evidence suggests that IL activity inhibits alcohol seeking (Marchant et al., 2010; Gass et al., 2014; Pfarr et al., 2015), but with exceptions (Willcocks and McNally, 2013). In contrast, IL inactivation reduces cued reinstatement of methamphetamine seeking (Rocha and Kalivas, 2010). With regard to opiates such as heroin and morphine, the evidence is mixed, with many studies showing a role for the IL in promoting opiate-seeking behavior (Rogers et al., 2008; Bossert et al., 2011; Bossert et al., 2012) and others showing a role for the IL in inhibiting such behavior (Ovari and Leri, 2008; Chen et al., 2016). Although beyond the scope of this discussion, it should be noted that there are many differences across these studies (types of reinstatement, types of manipulations) that may account for the discrepant results. Nonetheless, using closed-loop optogenetics to more precisely alter IL activity may be especially useful for addressing these differences.

\section{Conclusion}

The present findings advance the differential roles of mPFC subregions in regulating cocaine seeking and raise the question of whether impaired prefrontal plasticity resulting from long-term cocaine use alters the functional ability of the IL to provide inhibitory control for resisting the mechanisms underlying relapse (Brewer et al., 2008; Goldstein and Volkow, 2011; Radley et al., 2015). Combined with other studies on alcohol seeking (Gass and Chandler, 2013; Gass et al., 2014), this idea strongly points to the potential of strengthening IL-based systems in the treatment of some types of drug addiction.

\section{References}

Aragona BJ, Cleaveland NA, Stuber GD, Day JJ, Carelli RM, Wightman RM (2008) Preferential enhancement of dopamine transmission within the nucleus accumbens shell by cocaine is attributable to a direct increase in phasic dopamine release events. J Neurosci 28:8821-8831. CrossRef Medline

Augur IF, Wyckoff AR, Aston-Jones G, Kalivas PW, Peters J (2016) Chemogenetic activation of an extinction neural circuit reduces cue-induced reinstatement of cocaine seeking. J Neurosci 36:10174-10180. CrossRef Medline

Bossert JM, Stern AL, Theberge FR, Cifani C, Koya E, Hope BT, Shaham Y (2011) Ventral medial prefrontal cortex neuronal ensembles mediate context-induced relapse to heroin. Nat Neurosci 14:420-422. CrossRef Medline

Bossert JM, Stern AL, Theberge FR, Marchant NJ, Wang HL, Morales M, Shaham Y (2012) Role of projections from ventral medial prefrontal cortex to nucleus accumbens shell in context-induced reinstatement of heroin seeking. J Neurosci 32:4982-4991. CrossRef Medline

Brewer JA, Worhunsky PD, Carroll KM, Rounsaville BJ, Potenza MN (2008) Pretreatment brain activation during stroop task is associated with outcomes in cocaine-dependent patients. Biol Psychiatry 64:998-1004. CrossRef Medline

Burgos-Robles A, Vidal-Gonzalez I, Santini E, Quirk GJ (2007) Consolidation of fear extinction requires NMDA receptor-dependent bursting in the ventromedial prefrontal cortex. Neuron 53:871-880. CrossRef Medline

Chen W, Wang Y, Sun A, Zhou L, Xu W, Zhu H, Zhuang D, Lai M, Zhang F, Zhou W, Liu H (2016) Activation of AMPA receptor in the infralimbic cortex facilitates extinction and attenuates the heroin-seeking behavior in rats. Neurosci Lett 612:126-131. CrossRef Medline

Do-Monte FH, Manzano-Nieves G, Quiñones-Laracuente K, Ramos-Medina 
L, Quirk GJ (2015) Revisiting the role of infralimbic cortex in fear extinction with optogenetics. J Neurosci 35:3607-3615. CrossRef Medline

Gass JT, Chandler LJ (2013) The plasticity of extinction: contribution of the prefrontal cortex in treating addiction through inhibitory learning. Front Psychiatry 4:46. CrossRef Medline

Gass JT, Trantham-Davidson H, Kassab AS, Glen WB Jr, Olive MF, Chandler LJ (2014) Enhancement of extinction learning attenuates ethanolseeking behavior and alters plasticity in the prefrontal cortex. J Neurosci 34:7562-7574. CrossRef Medline

Goldstein RZ, Volkow ND (2011) Dysfunction of the prefrontal cortex in addiction: neuroimaging findings and clinical implications. Nat Rev Neurosci 12:652-669. CrossRef Medline

Grosenick L, Marshel JH, Deisseroth K (2015) Closed-loop and activityguided optogenetic control. Neuron 86:106-139. CrossRef Medline

Hafenbreidel M, Rafa Todd C, Twining RC, Tuscher JJ, Mueller D (2014) Bidirectional effects of inhibiting or potentiating NMDA receptors on extinction after cocaine self-administration in rats. Psychopharmacology (Berl) 231:4585-4594. CrossRef Medline

Hafenbreidel M, Twining RC, Rafa Todd C, Mueller D (2015) Blocking infralimbic basic fibroblast growth factor (bFGF or FGF2) facilitates extinction of drug seeking after cocaine self-administration. Neuropsychopharmacology 40:2907-2915. CrossRef Medline

Huff ML, Miller RL, Deisseroth K, Moorman DE, LaLumiere RT (2013) Posttraining optogenetic manipulations of basolateral amygdala activity modulate consolidation of inhibitory avoidance memory in rats. Proc Natl Acad Sci U S A 110:3597-3602. CrossRef Medline

Koya E, Uejima JL, Wihbey KA, Bossert JM, Hope BT, Shaham Y (2009) Role of ventral medial prefrontal cortex in incubation of cocaine craving. Neuropharmacology 56:177-185. CrossRef Medline

LaLumiere RT, Niehoff KE, Kalivas PW (2010) The infralimbic cortex regulates the consolidation of extinction after cocaine self-administration. Learn Mem 17:168-175. CrossRef Medline

LaLumiere RT, Smith KC, Kalivas PW (2012) Neural circuit competition in cocaine-seeking: roles of the infralimbic cortex and nucleus accumbens shell. Eur J Neurosci 35:614-622. CrossRef Medline

Ma YY, Lee BR, Wang X, Guo C, Liu L, Cui R, Lan Y, Balcita-Pedicino JJ, Wolf ME, Sesack SR, Shaham Y, Schlüter OM, Huang YH, Dong Y (2014) Bidirectional modulation of incubation of cocaine craving by silent synapse-based remodeling of prefrontal cortex to accumbens projections. Neuron 83:1453-1467. CrossRef Medline

Marchant NJ, Furlong TM, McNally GP (2010) Medial dorsal hypothalamus mediates the inhibition of reward seeking after extinction. J Neurosci 30:14102-14115. CrossRef Medline

McFarland K, Lapish CC, Kalivas PW (2003) Prefrontal glutamate release into the core of the nucleus accumbens mediates cocaine-induced reinstatement of drug-seeking behavior. J Neurosci 23:3531-3537. Medline

Milad MR, Quirk GJ (2002) Neurons in medial prefrontal cortex signal memory for fear extinction. Nature 420:70-74. CrossRef Medline

Moorman DE, Aston-Jones G (2015) Prefrontal neurons encode contextbased response execution and inhibition in reward seeking and extinction. Proc Natl Acad Sci U S A 112:9472-9477. CrossRef Medline
Ovari J, Leri F (2008) Inactivation of the ventromedial prefrontal cortex mimics re-emergence of heroin seeking caused by heroin reconditioning. Neurosci Lett 444:52-55. CrossRef Medline

Peters J, LaLumiere RT, Kalivas PW (2008) Infralimbic prefrontal cortex is responsible for inhibiting cocaine seeking in extinguished rats. J Neurosci 28:6046-6053. CrossRef Medline

Pfarr S, Meinhardt MW, Klee ML, Hansson AC, Vengeliene V, Schönig K, Bartsch D, Hope BT, Spanagel R, Sommer WH (2015) Losing control: excessive alcohol seeking after selective inactivation of cue-responsive neurons in the infralimbic cortex. J Neurosci 35:10750-10761. CrossRef Medline

Pinheiro JC, Bates DM (2000) Mixed-effects models in S and S-PLUS. New York: Springer.

R Core Team (2012) R: a language and environment for statistical computing. Vienna: R Foundation for Statistical Computing.

Radley JJ, Anderson RM, Cosme CV, Glanz RM, Miller MC, Romig-Martin SA, LaLumiere RT (2015) The contingency of cocaine administration accounts for structural and functional medial prefrontal deficits and increased adrenocortical activation. J Neurosci 35:11897-11910. CrossRef Medline

Rocha A, Kalivas PW (2010) Role of the prefrontal cortex and nucleus accumbens in reinstating methamphetamine seeking. Eur J Neurosci 31: 903-909. CrossRef Medline

Rogers JL, Ghee S, See RE (2008) The neural circuitry underlying reinstatement of heroin-seeking behavior in an animal model of relapse. Neuroscience 151:579-588. CrossRef Medline

Stefanik MT, Moussawi K, Kupchik YM, Smith KC, Miller RL, Huff ML, Deisseroth K, Kalivas PW, LaLumiere RT (2013) Optogenetic inhibition of cocaine seeking in rats. Addict Biol 18:50-53. CrossRef Medline

Stujenske JM, Spellman T, Gordon JA (2015) Modeling the spatiotemporal dynamics of light and heat propagation for in vivo optogenetics. Cell Rep 12:525-534. CrossRef Medline

Van den Oever MC, Rotaru DC, Heinsbroek JA, Gouwenberg Y, Deisseroth K, Stuber GD, Mansvelder HD, Smit AB (2013) Ventromedial prefrontal cortex pyramidal cells have a temporal dynamic role in recall and extinction of cocaine-associated memory. J Neurosci 33:18225-18233. CrossRef Medline

Warren BL, Mendoza MP, Cruz FC, Leao RM, Caprioli D, Rubio FJ, Whitaker LR, McPherson KB, Bossert JM, Shaham Y, Hope BT (2016) Distinct Fos-expressing neuronal ensembles in the ventromedial prefrontal cortex mediate food reward and extinction memories. J Neurosci 36:6691-6703. CrossRef Medline

West EA, Saddoris MP, Kerfoot EC, Carelli RM (2014) Prelimbic and infralimbic cortical regions differentially encode cocaine-associated stimuli and cocaine-seeking before and following abstinence. Eur J Neurosci 39: 1891-1902. CrossRef Medline

Willcocks AL, McNally GP (2013) The role of medial prefrontal cortex in extinction and reinstatement of alcohol-seeking in rats. Eur J Neurosci 37:259-268. CrossRef Medline

Yizhar O, Fenno LE, Davidson TJ, Mogri M, Deisseroth K (2011) Optogenetics in neural systems. Neuron 71:9-34. CrossRef Medline 